\title{
Jogos Eletrônicos e a Inclusão da Criança com Deficiência na Escola
}

\author{
Marcos Vinícius Guimarães de Paula* \\ Flávia Karla Soares**
}

\begin{abstract}
Resumo
Este trabalho objetiva discutir a respeito do uso de jogos eletrônicos como recurso pedagógico no trabalho com a criança com deficiência na escola, abordando algumas questões desafiadoras apresentadas para uma busca de reflexões, em torno das constantes evoluções da sociedade, especialmente no que diz respeito à inclusão tecnológica dos estudantes deficientes. Assim, buscou-se incorporar diálogos voltados para a ação do educador e das crianças, visando encontrar caminhos para a aplicabilidade dos jogos eletrônicos nos processos de ensino e de aprendizagem no espaço escolar. Além disso, o texto relata experiências pedagógicas inclusivas desenvolvidas em uma escola pública da rede municipal de ensino Anápolis-Goiás, sendo que um aluno com deficiência intelectual e uma aluna com deficiência visual vivenciaram alguns jogos eletrônicos no computador. Desse modo, conclui-se que o uso de jogos eletrônicos nos processos formativos envolvendo a criança com deficiência contribui para o desenvolvimento de habilidades motoras e cognitivas, para novas aprendizagens e também para a inclusão digital, educacional e social.
\end{abstract}

Palavras-chave: jogos eletrônicos, criança, deficiência, inclusão.

Electronic Games and the Inclusion of the Child with Deficiency in the School

Abstract

This research aims to discuss the use of electronic games as a pedagogical resource in the work with children with disabilities at school, addressing some challenging questions presented for a search for reflections, around the constant evolution of society, especially with regard to technological inclusion of disabled students. Thus, we try to incorporate dialogues aimed at the action of the educator and children, aiming to find ways for the applicability of electronic games in the teaching and learning processes in the school space. In addition, the text reports inclusive pedagogical experiences developed in a public school in the municipal school of Anápolis-Goiás, where a student with intellectual disability and a student with visual deficiency experienced some electronic games on the computer. Thus, it is concluded that the use of electronic games in training processes involving children with disabilities contributes to the development of motor and cognitive skills, to new learning and also to digital, educational and social inclusion.

Keywords: electronic games, child, disability, inclusion.

\section{Introdução}

Tendo como cenário a realidade educacional no contexto dos avanços tecnológicos, o presente trabalho dedica-se a discutir sobre o uso de jogos eletrônicos na escola para incluir a criança com deficiência. Problematiza-se o uso das ferramentas

\footnotetext{
* Doutorando em Educação pela Universidade de Brasília/UnB. Professor de Educação Física na rede municipal de ensino de Anápolis-GO. E-mail: marcosviniciusguimaraesdepaula@ outlook.com.

** Mestre em Educação, Linguagem e Tecnologias pela Universidade Estadual de Goiás/UEG. Professora da rede municipal de ensino de Caldas Novas-GO e da Universidade Estadual de Goiás/Campus Pires do Rio.E-mail: fkarlak@ hotmail.com.
} 
tecnológicas como recurso pedagógico e como suporte para os processos de ensino e de aprendizagem dos educandos com necessidades educacionais especiais, defendendo a escola como promotora da justiça social ao combater a exclusão de todo ser humano, e, em especial, dos estudantes deficientes.

Neste texto, dá-se atenção aos estudantes com necessidades educacionais especiais, destacando a deficiência intelectual e a visual. Acredita-se ser necessário estimular a independência da pessoa com deficiência, disponibilizando o acesso aos jogos eletrônicos a fim de desbravar possibilidades de articulação entre ser o humano e a máquina. Nesse entendimento, o trabalho destaca a inclusão escolar das crianças com deficiência como um elemento imprescindível para alcançar a justiça social, visto que ela "é um processo que reitera princípios democráticos de participação social plena" (SANTOS, 2003, p. 81).

Ademais, o texto compartilha experiências inclusivas com o uso de jogos eletrônicos no computador realizadas em uma escola pública da rede municipal de ensino de Anápolis-Goiás. Foi possível compreender que o uso de games nos processos educativos da criança com deficiência colaborou para o desenvolvimento de habilidades motoras e cognitivas, para novas descobertas e para incluir tecnologicamente e socialmente.

\section{TDICs e Inclusão}

Já não há mais espaço para uma escola segregadora e desumana. É imprescindível construir uma escola inclusiva para respeitar e acolher as diferenças de cada ser humano. Dessa forma, torna-se necessário pensar sobre a importância do desenvolvimento de práticas pedagógicas formativas e inclusivas no ambiente escolar.

Concorda-se com a ideia de construir uma escola das diferenças que contemple uma educação como prática de liberdade (FREIRE, 2000), não negligenciando ou esquecendo as pessoas com deficiência. Urge refletir sobre caminhos metodológicos para incluir estudantes com necessidades educativas especiais, respeitando os seus tempos de aprendizagem e suas identidades. Defende-se que promover processos inclusivos escolares coopera para uma educação mais humana e mais solidária (MANTOAN, 2003). 
As tecnologias digitais da informação e comunicação (TDICs) trazem a possibilidade de democratização e de universalização da informação com grande potencialidade para diminuir a exclusão e colaborar para a justiça social, visando estimular a produção de conhecimento de maneira criativa. A inclusão das crianças com deficiência reitera os princípios democráticos com vistas à participação na sociedade de forma efetiva e plena. Incluir contempla o envolvimento de qualquer cidadão nas diversas arenas sociais, combatendo as injustiças ao garantir os seus direitos (SANTOS, 2003).

Nesse caminho, o presente trabalho discute o uso das TDICs na educação escolar para colaborar na inclusão. As TDICs podem ser utilizadas como instrumentos pedagógicos, uma vez que ajudam na socialização e na democratização dos saberes, oportunizam aprendizagens sobre as mídias e a linguagem das máquinas (LIBÂNEO, 2000), tornando o processo de ensino mais atrativo e criativo, o que acaba por potencializar o aprendizado. Ademais, podem ajudar na inclusão dos que durante muito tempo foram marginalizados. Fazer o uso das TDICs com os educandos deficientes é um desafio para o professor sensível e comprometido com a sua função social de acolher e de ensinar todo sujeito humano. Para ensinar a todos, independentemente das diferenças de cada um, é imprescindível passar de um ensino transmissivo para uma pedagogia ativa, dialógica, interativa, conexional, que se contrapõe a toda e qualquer visão unidirecional, de transferência unitária, individualizada e hierárquica do saber (MANTOAN, 2002).

\section{Método}

Este trabalho consiste em um breve estudo bibliográfico e com análise empírica. Trata-se de um estudo descritivo do tipo relato de experiência (GIL, 2008). Dessa maneira, são compartilhadas a seguir algumas intervenções pedagógicas inclusivas com o uso do computador, que foram desenvolvidas em uma escola da rede municipal de ensino de Anápolis-Goiás, durante o primeiro semestre letivo do ano de 2019.

Participaram das experiências dois estudantes com necessidades educacionais especiais, sendo um educando com deficiência intelectual e uma educanda com deficiência visual (cega totalmente de um olho e com baixa visão do outro). Nelas, os estudantes vivenciaram alguns jogos no computador, conhecendo um mundo novo de possibilidades. 
Nesse texto, o educando será denominado de estudante A e a aluna denominada de estudante $\mathrm{B}$, resguardando suas identidades. $\mathrm{O}$ estudante A cursa o sétimo ano do ensino fundamental e a estudante B está no sexto ano. Vale destacar que houve autorização dos responsáveis para a divulgação das imagens presentes neste estudo e que ainda assim, os rostos das crianças foram desfocados.

Cabe dizer que o professor de Educação Física da escola foi o responsável pelas atividades propostas, atendendo os dois educandos individualmente, em horário diferenciado das aulas de Educação Física das turmas nas quais eles estudavam. Trata-se de um atendimento educacional especializado que abrange atividades corporais e atividades com o uso das tecnologias.

\section{Resultados e Discussões}

Inicialmente, é importante dizer que ambos os estudantes conheciam muito pouco do computador. O professor percebeu que as suas experiências com o computador em casa eram poucas ou inexistentes. Assim sendo, explicou aos educandos o que era o computador e seus componentes principais, destacando o mouse, o monitor e o teclado. Nas figuras 1 e 2 abaixo podemos observar o estudante A identificando esses conceitos trabalhados pelo professor.

Figura 1 - Estudante A indicando o monitor

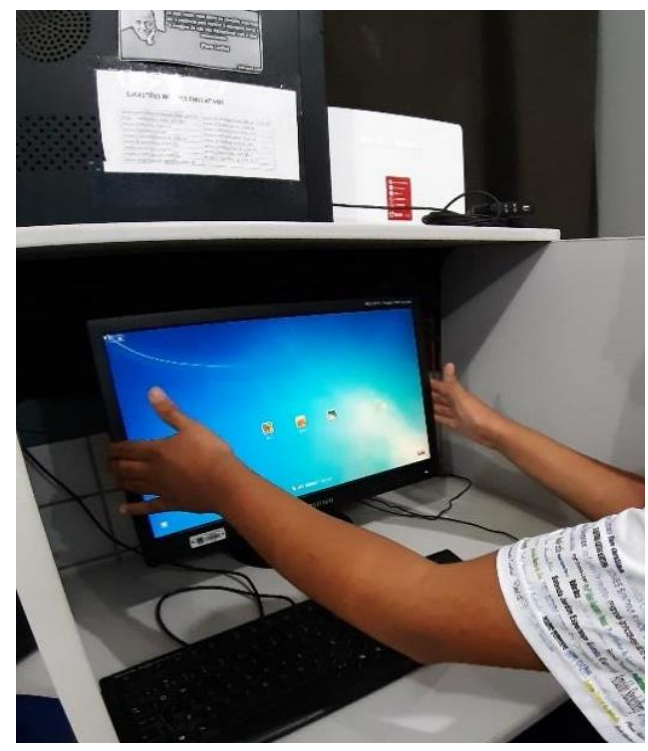

Fonte: acervo dos autores, 2019. 
Figura 2 - Estudante A indicando o teclado

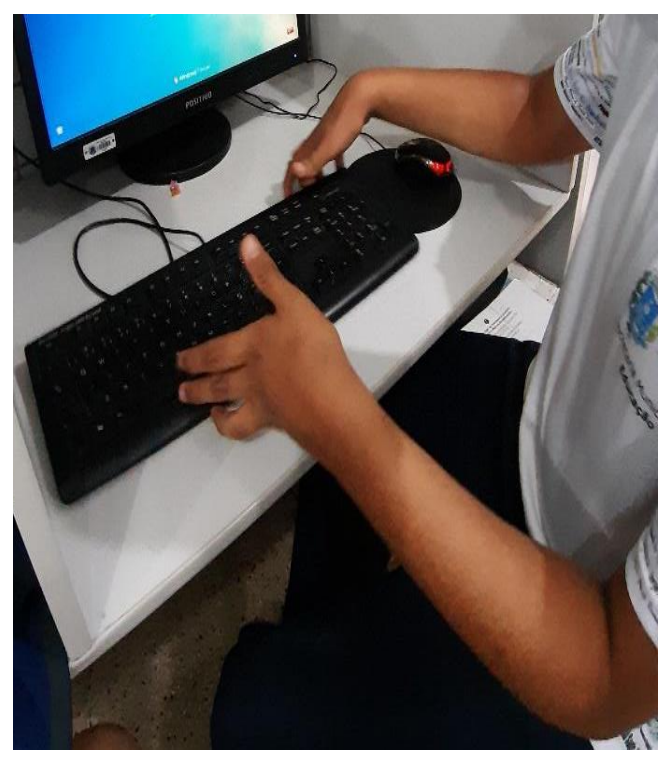

Fonte: acervo dos autores, 2019.

Um dos grandes desafios encontrados ao trabalhar com o estudante A foi a impaciência dele ao segurar o mouse e clicar quando era necessário. A fragilidade da coordenação motora fina do aprendiz foi percebida pelo professor logo no início do trabalho. Contudo, o professor procurou acalmar o educando durante as aulas, afirmando que com o passar do tempo, ele melhoraria e não sentiria mais tamanha dificuldade. E de fato isso ocorreu. No final do primeiro semestre letivo de 2019 foi possível observar que o estudante A teve sua coordenação motora fina aprimorada consideravelmente.

Durante as aulas, o professor optou em trabalhar com os dois estudantes alguns jogos pelo computador, sendo que em função da deficiência visual nem todos os jogos vivenciados pelo estudante A foram possíveis de serem trabalhados com a estudante B. É válido destacar que o uso do computador como ferramenta pedagógica torna o processo de ensino mais atraente e envolvente, permitindo que o educando apreenda de forma autônoma (VALENTE, 1991).

Nesse caminho, entende-se que o uso de jogos eletrônicos encanta os educandos com a sua ludicidade, estimulando-os para o aprendizado. Ademais, concorda-se com Moita (2010, p. 116) ao afirmar que o jogo eletrônico permite: 
do computador em aparato de comunicação e da convergência das mídias. Proporciona, dessa forma, novas formas de sentir, pensar, agir e interagir.

Isto posto, relataremos inicialmente as experiências com o estudante A. Um dos jogos experimentados com esse educando pode ser observado na figura 3 a seguir. Com ele foi possível estudar as formas geométricas, sendo que na medida em que as fases do jogo eram concluídas, figuras mais complexas apareciam e eram apreendidas. E assim, foi possível trabalhar a identificação e o conceito das formas geométricas.

Figura 3 - Jogo das formas geométricas

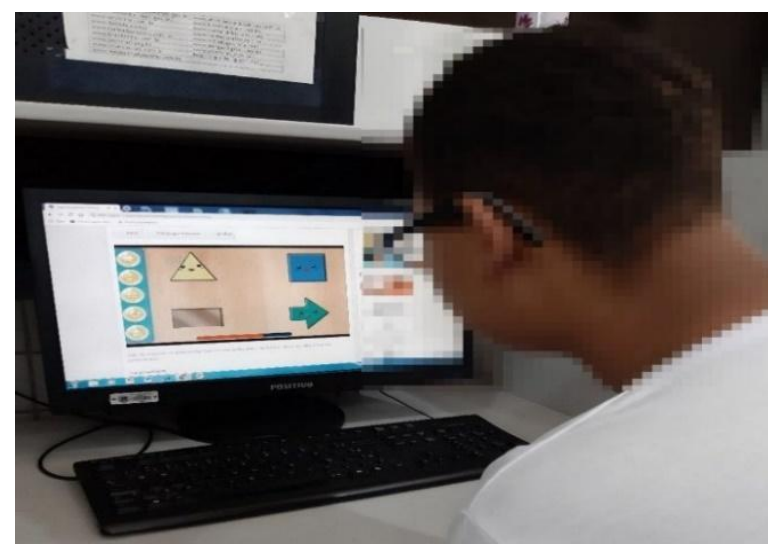

Fonte: acervo dos autores, 2019.

Com o objetivo de desenvolver a noção de espaço (frente, trás, esquerda e direita), o professor indicou um jogo de labirinto, no qual o educando tinha que levar uma "formiga" até o final do percurso para poder mudar de fase. Embora possa parecer um jogo simples, para o estudante A era complexo. É preciso frisar que o educando em questão possui uma deficiência intelectual e, por isso, durante o decorrer do jogo parava e demorava um pouco para raciocinar o que deveria fazer com a "formiguinha", isto é, se a levava para frente ou para o lado. Outro jogo usado para trabalhar a noção de espaço foi um em que o estudante A tinha que lançar a bola para a direita ou esquerda, enganando o goleiro para fazer o gol. As figuras 4 e 5 abaixo indicam esses dois jogos em questão. 
Figura 4 - Jogo do labirinto

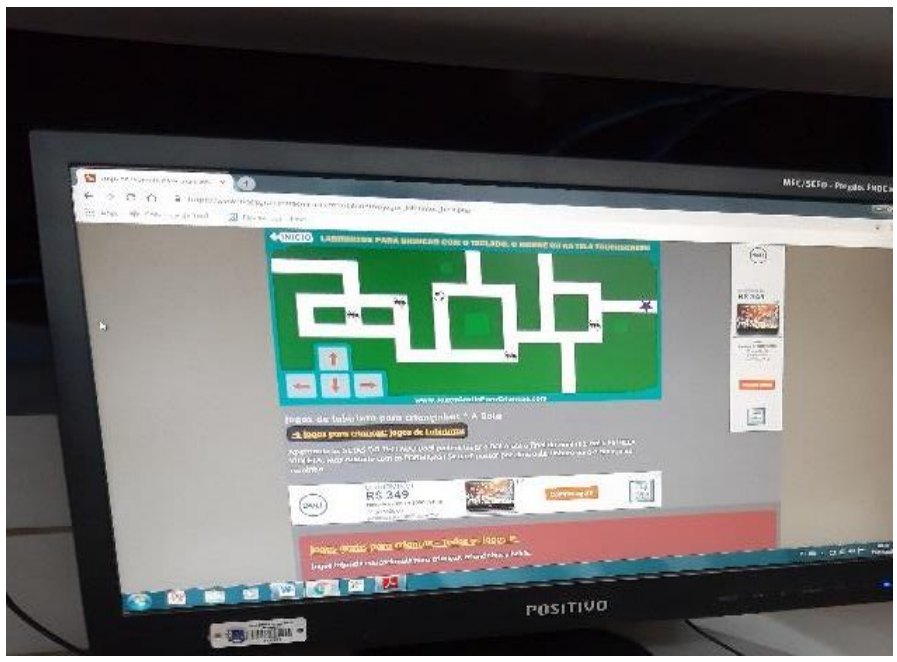

Fonte: acervo dos autores, 2019.

Figura 5 - Jogo do futebol

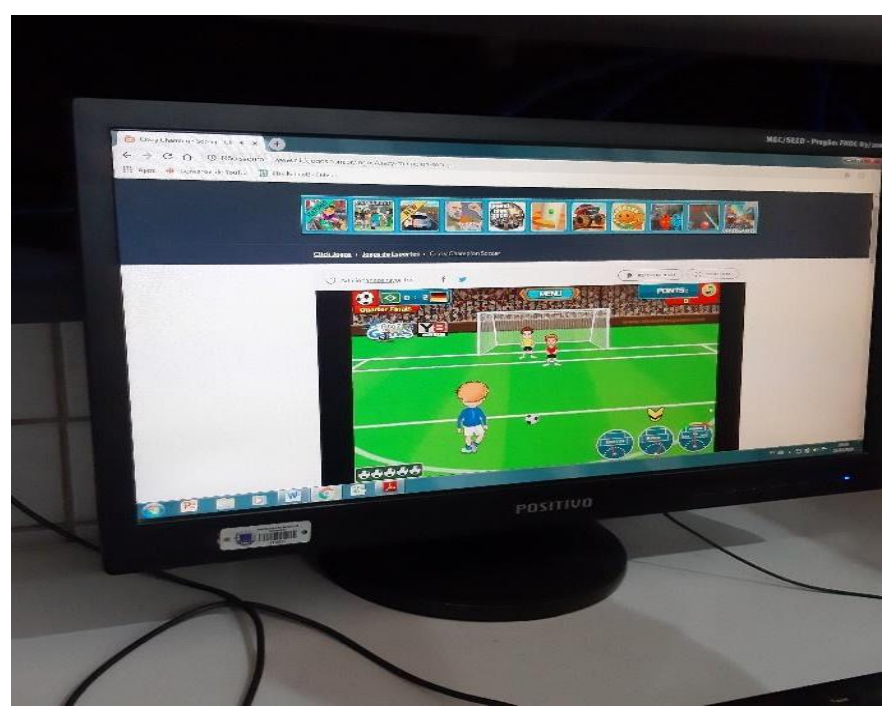

Fonte: acervo dos autores, 2019.

Vale destacar que o professor procurou respeitar o ritmo do educando, não cobrando que ele fosse rápido no desenvolvimento dos jogos, pois concorda-se com Barreto e Reis (2011) ao dizerem que cada educando tem desempenhos diferentes na sua relação com o conhecimento.

Além dos jogos já citados, alguns foram utilizados para trabalhar as cores e desenvolver experiências estéticas com o estudante A. Na próxima imagem é possível acompanhar um jogo que evidenciava as cores. Nele, o estudante A tinha que clicar apenas nas bolas cujas cores estavam sendo indicadas no início da tela. E ele tinha um 
determinado tempo (segundos) para realizar a atividade. A figura 6 ilustra o game em questão.

Figura 6 - Jogo das bolas coloridas

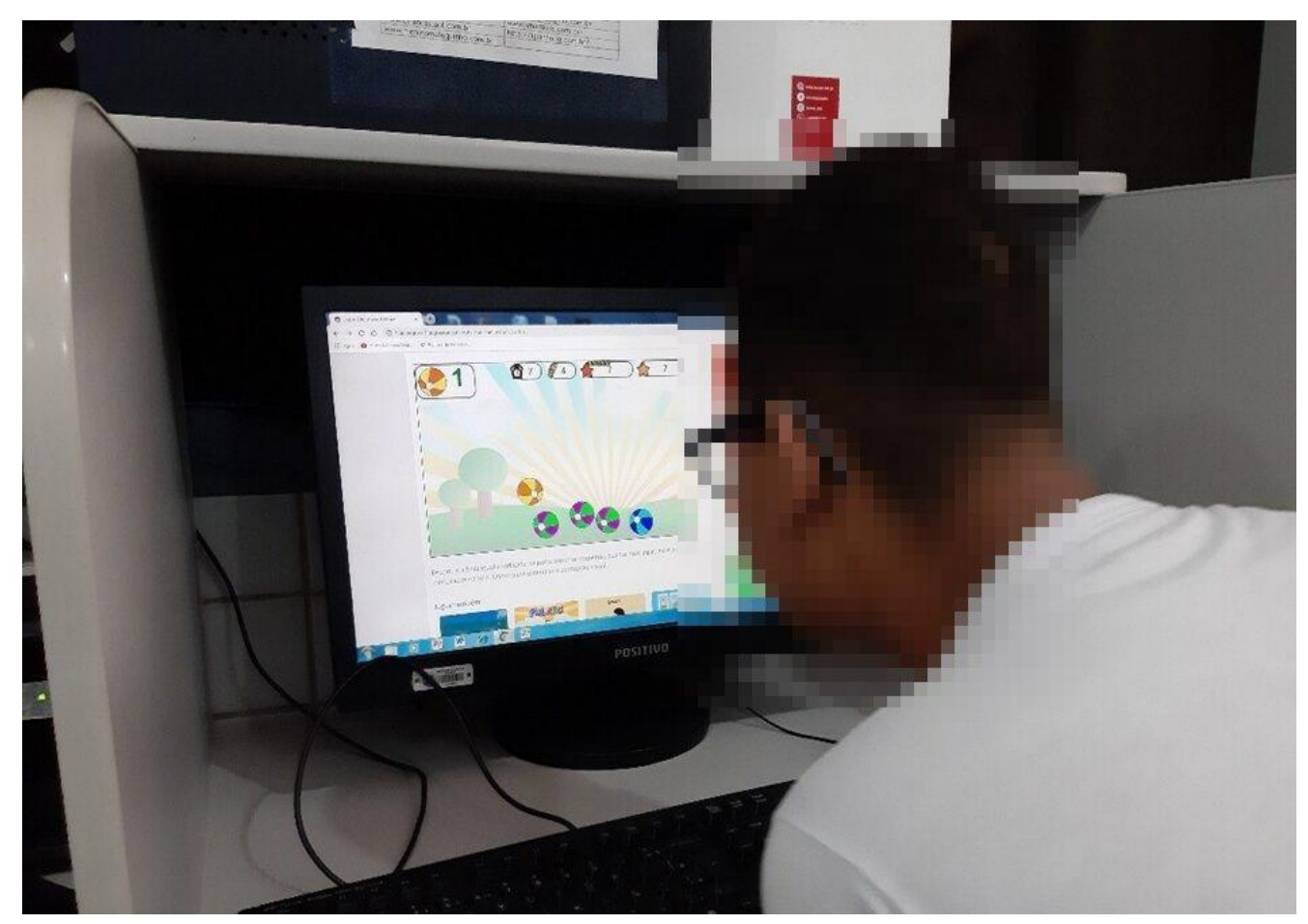

Fonte: acervo dos autores, 2019.

Já nas próximas imagens ( 7 e 8 ) podemos verificar um jogo em que o estudante A coloriu alguns desenhos. Optou-se por trabalhar figuras referentes ao universo dos esportes, objetivando identificar algumas práticas esportivas e desenvolver uma vivência estética tecnológica. Entende-se que é fundamental pensar e desenvolver uma educação estética com os aprendizes com necessidades especiais. Toda criança precisa de uma educação que toque as emoções, visto que a sensibilidade humana não pode ser esquecida na educação escolar (NICOLESCU, 2005). 
Figura 7 - Colorindo o futebol

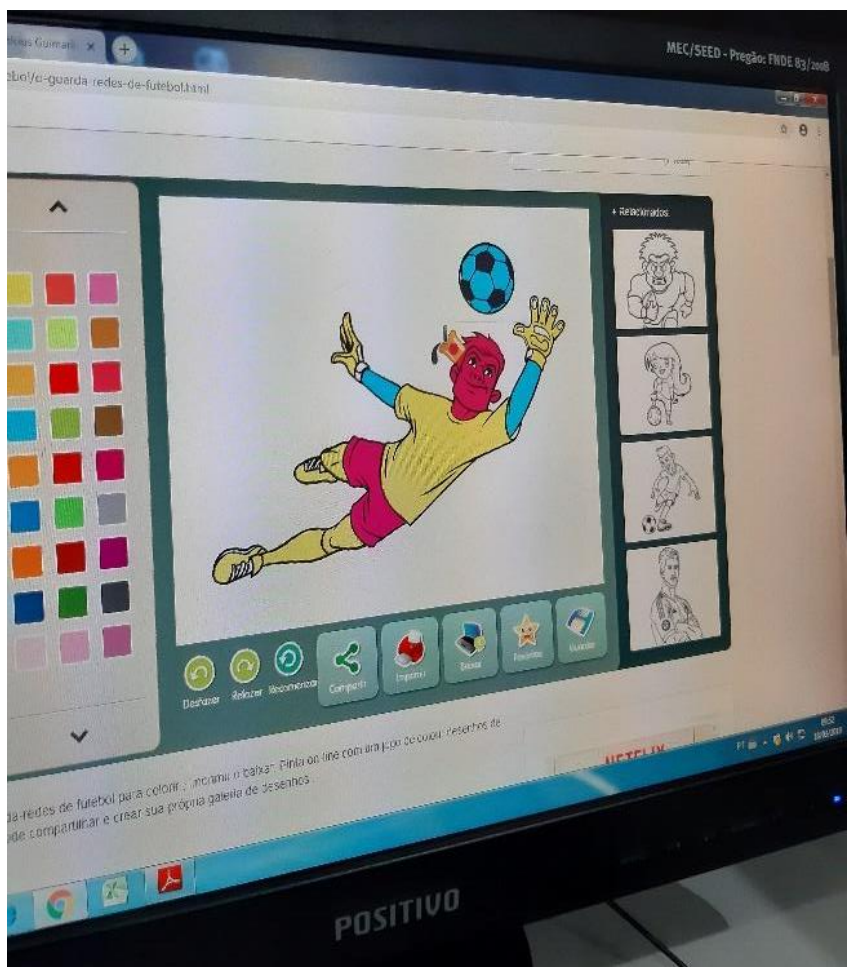

Fonte: acervo dos autores, 2019.

Figura 8 - Colorindo o basquete

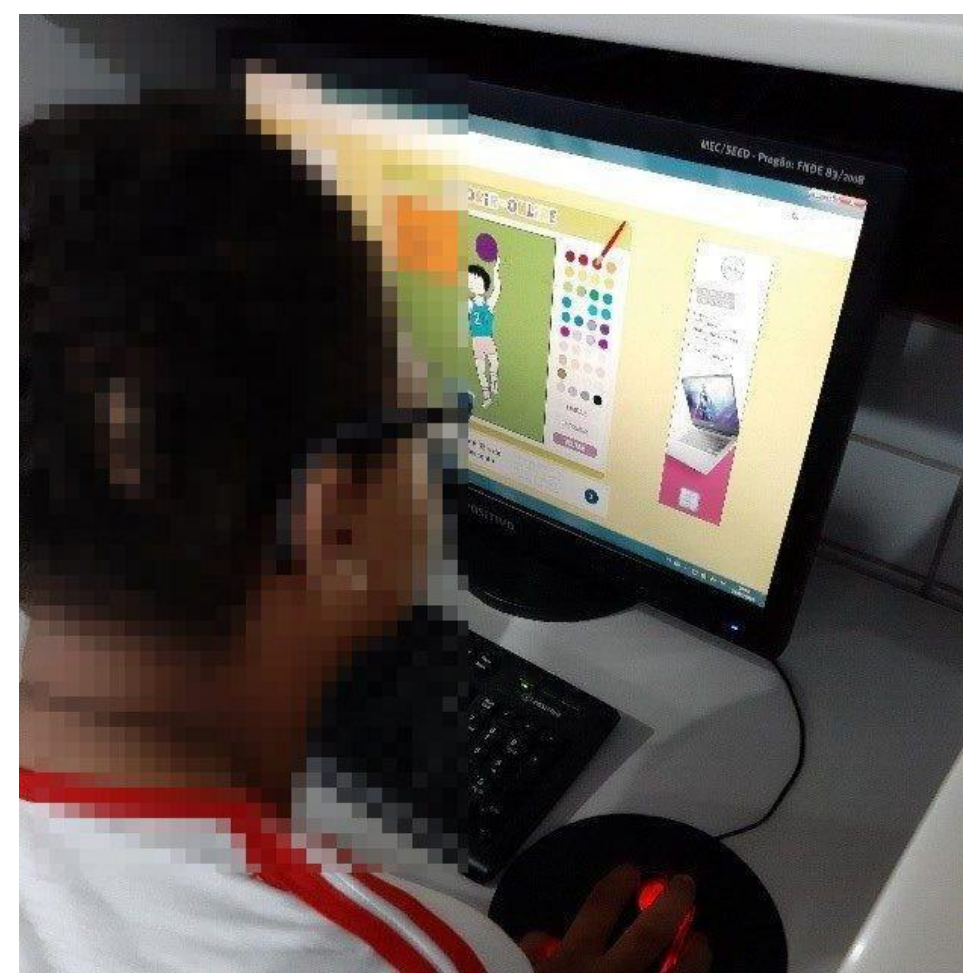

Fonte: acervo dos autores, 2019. 
Nesse momento, compartilharemos algumas experiências com o uso de jogos eletrônicos desenvolvidas com a estudante B. Cabe dizer que em função da deficiência visual o trabalho com essa aluna foi um grande desafio, principalmente para o professor. Foram testados vários jogos para encontrar os que ela conseguia jogar sem grandes dificuldades. Algumas medidas foram adotadas para facilitar o desenvolvimento das atividades com a estudante B, a saber: foi utilizado o computador do laboratório de informática cujo monitor era o maior, o zoom do monitor foi aumentado e o cursor do mouse também.

Um dos jogos utilizados com a estudante B consistia em descobrir qual bicho estava escondido na tela. Para isso, a educanda tinha que passar o cursor do mouse por toda a tela e, assim, as partes que escondiam o bicho iam sumindo até que toda a imagem ficasse visível. A educanda conseguiu descobrir os animais aproximando bem o seu rosto do monitor. Podemos observar o desenvolvimento desse jogo na imagem 9 a seguir.

Figura 9 - Jogo descobrindo o bicho

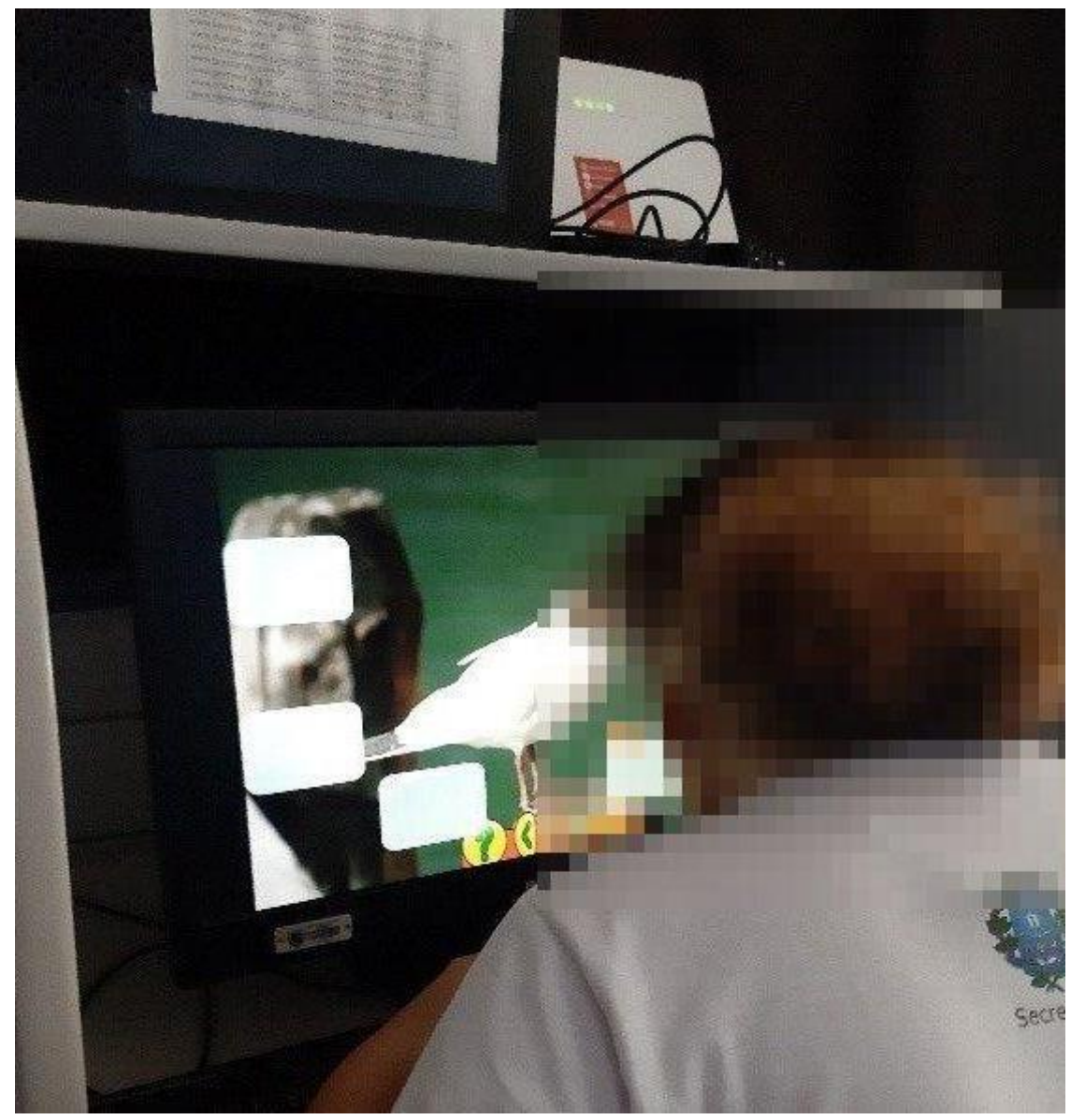

Fonte: acervo dos autores, 2019. 
A estudante B mostrou-se extremamente eufórica durante o jogo descobrindo o bicho, ao ponto que chegou a gritar de alegria durante a atividade. Destarte, destacamos a importância de a escola ser um espaço de aventuras do conhecimento para as crianças com deficiência. A escola precisa oportunizar atividades inclusivas para novas e significativas aprendizagens. Outro jogo lúdico que a estudante B vivenciou foi o jogo da memória, como é possível observar na figura 10.

Figura 10 - Jogo da memória

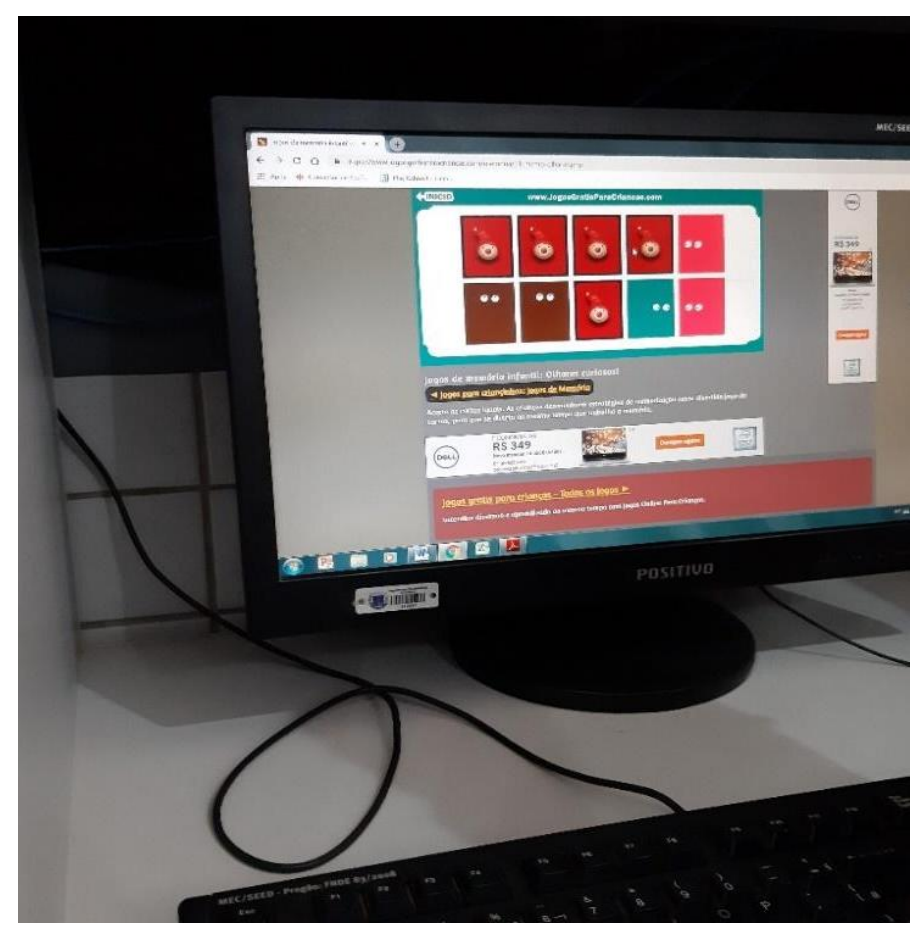

Fonte: acervo dos autores, 2019.

Dessa forma, destaca-se que o uso dos jogos eletrônicos no computador abriu um universo novo e desconhecido para os estudantes A e B, repleto de diversão, novidade e aprendizagem. Vale destacar uma fala da estudante B, dita em uma das últimas aulas do semestre. Ela disse ao seu professor: "Eu sou apaixonada nesses jogos". Essa fala permite pensar que a escola deve ser um espaço de oportunidades para apreender e para ajudar o aluno com deficiência em novos voos. Durante todas as aulas foi notório o entusiasmo e o encantamento dos dois educandos, ao fazer uso do computador nas atividades educativas. Nesse caminho, Bortolini et al. (2012) afirmam que: 
É preciso, contudo, perceber a inserção dos recursos das tecnologias da informação e da comunicação na escola para além da inclusão digital, mediante a apropriação destes recursos enquanto instrumentos que estendem a capacidade humana de armazenar, resgatar, explorar e divulgar a informação. Neste contexto, a escola é desafiada a observar, reconhecer, apropriar-se e contribuir para com a consolidação de uma nova cultura de aprendizagem ( $\mathrm{p}$. 142).

Em suma, avalia-se que o uso de games nos processos formativos da criança com deficiência pode colaborar para o desenvolvimento de habilidades motoras e cognitivas como a coordenação motora fina, a atenção, a memória de trabalho, o raciocínio, dentre outras. Além disso, pontua-se que os games podem ajudar na inclusão e na justiça social, ao gerar oportunidades de vivências e de aprendizagens para os estudantes deficientes.

\section{Considerações Finais}

A escola é um espaço para o desenvolvimento humano, sendo fundamental acolher, respeitar e educar a pessoa com deficiência. Para isso, é importante desenvolver atividades inclusivas. Defende-se que as TDICs sejam utilizadas nos processos de ensino e de aprendizagem dos alunos com necessidades educacionais especiais, respeitando as suas especificidades e os seus limites. As TDICs são fortes aliadas para promover a inclusão no espaço escolar, pois oportunizam novas formas de aprender a quem durante muito tempo foi excluído e esquecido. Elas colaboram para abrir o mundo dos saberes para todo ser humano, incluindo a pessoa com deficiência. Por conseguinte, elas podem contribuir, juntamente com a mediação dos professores, para a justiça social ao possibilitarem experiências pedagógicas sensíveis e transformadoras.

Neste sentido, as experiências inclusivas relatadas neste texto revelam que o uso de jogos eletrônicos pelo computador torna o processo de ensino mais lúdico, atrativo e inovador, tornando o processo de aprendizagem mais significativo e autônomo. Portanto, compreende-se que o uso das TDICs na escola ajuda na inclusão digital e, consequentemente, na inclusão social do educando com deficiência. Vislumbra-se uma escola enquanto espaço de compreensão humana (MORIN, 2017), onde todo ser humano seja tratado com zelo, carinho e cuidado. Uma escola promotora da justiça social e do desenvolvimento humano se faz urgente. 


\section{Referências}

BARRETO, C. S. G.; REIS, M. B. de F. Educação inclusiva: do paradigma da igualdade para o paradigma da diversidade. Polyphonía, v. 22, n. 1, p. 19-32, jan./jun. 2001.

BORTOLINI, A.; GRÄBIN, C.; GERHARDT, L. M.; PEREIRA, L. B.; SCHERER, M. S.; BERSCH, M. E. Reflexões sobre o uso das tecnologias digitais das informações e da comunicação no processo educativo. Revista Destaques acadêmicos, v. 4, n. 2, p. 141150, abr./jun. 2012.

FREIRE, P. Educação como prática de liberdade: a sociedade brasileira em transição. Rio de Janeiro: Paz e Terra, 2000.

GIL, A. C. Como elaborar projetos de pesquisa. 5. ed. São Paulo: Atlas, 2008.

LIBÂNEO, J. C. Adeus professor, Adeus Professora? Novas tecnologias educacionais e profissão docente. 4. ed. São Paulo: Cortez, 2000.

MANTOAN, M. T. E. Ensinando a turma toda: as diferenças na escola. Pátio. Porto Alegre, v. 5, n. 20, p. 18-28, fev./abr. 2002.

MANTOAN, M. T. E. Inclusão Escolar: O que é? Por Quê? Como Fazer? São Paulo: Moderna, 2003.

MOITA, F. M. G. Os Games e o Ensino de História: uma reflexão sobre possibilidades de novas práticas educativas. Plurais. Salvador, v. 1, n. 2, p. 115-130, maio/ago, 2010.

MORIN, Edgar. A cabeça bem-feita: repensar a reforma, reformar o pensamento. 23. ed. Rio de Janeiro: Bertrand Brasil, 2017.

NICOLESCU, Basarab. Nós, a partícula e o universo. Lisboa: Ésquilo, 2005.

SANTOS, Mônica Pereira dos. O papel do ensino superior na proposta de uma educação inclusiva. Movimento, Niterói, v. 1, n. 7, p. 78-91, Maio. 2003.

VALENTE, J. A. Liberando a mente: computadores na educação especial. Campinas: Graf. Central da UNICAMP, 1991. 